\title{
Associations Between School Mental Health Team Membership and Impact on Service Provision
}

\author{
Samantha Reaves ${ }^{1}(1)$. Jill Bohnenkamp ${ }^{1}$. Ashley Mayworm ${ }^{2} \cdot$ Margaret Sullivan $^{3} \cdot$ Elizabeth Connors $^{1,4}$. \\ Nancy Lever ${ }^{1} \cdot$ Michael S. Kelly $^{2}$. Eric J. Bruns ${ }^{5}$. Sharon Hoover ${ }^{1}$
}

Accepted: 2 December 2021 / Published online: 5 January 2022

(c) The Author(s), under exclusive licence to Springer Science+Business Media, LLC, part of Springer Nature 2022

\begin{abstract}
Schools are the most common venue in which children and youth receive mental health services. To organize delivery of mental health care to such a large number of children, use of school teams is often recommended. Yet, there is limited empirical literature about the composition of school mental health teams or teams' relations to service provision. This study investigated team composition, including team multidisciplinarity (number of different types of professionals) and the presence of a community provider, and the relations of these two variables to service provision at Tier 1 (mental health promotion), Tier 2 (early intervention) and Tier 3 (intensive treatment) for 386 schools representing different school sizes, locations, and urbanicity. Results suggested team multidisciplinarity and the presence of a community provider were related to more frequent endorsement of service provision at schools. Practice and research implications are discussed including possible application to hiring decisions and further research with longitudinal data and information on service quality.
\end{abstract}

Keywords School mental health $\cdot$ Workforce $\cdot$ Teams $\cdot$ Service provision

\section{Introduction}

Rates of diagnosable mental health disorders in children and adolescents (hereafter referred to as "youth") are at historical highs and rising, especially related to the COVID-19 pandemic (Houtrow et al., 2014; Loades et al., 2020; National Academies of Sciences, Engineering, and Medicine., 2015). Yet, less than half of youth who would benefit from mental health intervention access treatment (Whitney \& Peterson, 2019). When youth do successfully access treatment, schools are one of the primary locations where they receive mental health care in the United States, with a recent meta-analysis

Samantha Reaves

sreaves@som.umaryland.edu

1 National Center for School Mental Health, University of Maryland School of Medicine, Baltimore, USA

2 Loyola University Chicago, Chicago, USA

3 University of Minnesota, Minneapolis, USA

4 Yale University, New Haven, USA

5 School Mental Health Assessment, Research, and Training Center, University of Washington School of Medicine, Seattle, USA suggesting rates are comparable to, if not higher than, rates of care in outpatient settings (Duong et al., 2020).

The school setting has many advantages over other treatment settings, including the potential to increase access to needed services for marginalized populations, providing a natural setting for generalization and maintenance of behavioral health skills, and offering access to a multidisciplinary array of mental health professionals (e.g., school psychologists, social workers, counselors, behavior specialists, nurses, teachers; Stephan \& Mayworm, 2017). Because of the depth and breadth of students' needs and the diversity of the school mental health (SMH) workforce, researchers, administrators, and policy-makers consistently recommend that organization of SMH care be managed within districtand school-level teams (Barrett et al., 2013; Hoover \& Bostic, 2021; OSEP Technical Assistance Center on Positive Behavioral Interventions and Supports, 2015) However, very little is known about the characteristics of SMH teams "in the real world." Better understanding of the composition and impact of SMH teams holds promise to advance research on SMH teamwork as well as development of best practice guidelines.

The current study aims to fill this knowledge gap by exploring characteristics of SMH teams nationally, including 
team composition across professional roles (e.g., school psychologists, social workers, nurses, teachers), types of SMH services provided, and how these variables vary by characteristics of the school (e.g., urbanicity, school size, and student demographics). In the rest of this introduction, we describe prior theory and research on SMH frameworks, teams and teamwork.

\section{Features of Comprehensive School Mental Health Services}

The presence of these SMH professionals is one core feature of comprehensive SMH systems (CSMHS), which include multi-tiered prevention, early intervention, and treatment services and supports that "promote positive school climate, social and emotional learning, and mental health and wellbeing, while reducing the prevalence and severity of mental illness" (Hoover et al., 2019, p. 13). CSMHS have gained momentum and support in recent years, as evidenced by the emphasis on mental health supports in the Every Student Succeeds Act, as well as state legislation requiring mental health education in K-12 schools (e.g., New York, Virginia; Vestal, 2018). The delivery of mental health supports in the school setting varies widely across schools, districts, states, and jurisdictions. There is also variation among service providers, service recipients, and the nature and comprehensiveness of those services (Hoover \& Bostic, 2021).

While national data on the staffing and service array offered in schools is limited, several student instructional support professional organizations endorse a recommended number and practitioner-to-student ratios. For example, the American School Counselor Association (ASCA) recommends 1 counselor per 250 students, the National Association of School Psychologists (NASP) recommends 1 school psychologist per 500-700 students, and the School Social Work Association of American (SSWAA) recommends 1 school social worker per 250 students; (Bastian et al., 2019). However, these are ideal ratios and many schools do not meet these recommendations.

A 2005 report from the Substance Abuse and Mental Health Services Administration (SAMHSA; Foster et al., 2005) summarized mental health service data from the 2002-2003 school year at thousands of schools and concluded that basic mental health services were widely available in schools. Many schools employed at least one part-time mental health professional or contracted for services with community mental health provider organizations. School building-level teams, whose responsibilities included mental health service provision to students, were also common. These teams typically included between 2 and 5 members; common school or district employed team members included school counselors, school psychologists, nurses, and social workers (Foster et al., 2005). Though useful for a broad overview, this report and other existing literature do not provide a clear picture of the types of professionals who serve on school mental health (SMH) teams, the types of services typically provided across a continuum from universal mental health promotion activities (Tier 1) to intensive treatment (Tier 3), how teams vary by school demographic variables, or how these variables relate to one other. Additionally, the SAMSHA data is almost two decades old and likely does not reflect current service delivery and professional representation accurately. In 2014, The National Quality Initiative, funded by Health Resources and Service Administration, tackled this gap in the literature and tasked the National Center for School Mental Health (NCSMH) to develop national performance standards and to collect updated data on the functioning of CSMHs including teaming structures (Connors et al., 2016). The data presented in this article are a result of that effort.

\section{Multi-tiered Systems of Support for SMH}

Best practice guidelines for providing academic, social-emotional, and behavioral support in schools are often organized using a three-tier "Multi-Tiered System of Supports" (MTSS) framework that promotes the success and wellbeing of an entire school population (Barret et al., 2013; Cappella et al., 2008; Hoover et al., 2019). Tier 1 (universal mental health promotion) provides all students with mental health promotion services, which may include social-emotional learning, wellness initiatives, positive teacher-student relationships, and positive behavior expectations. Tier 2 (targeted mental health prevention and early intervention), offers students, who are at-risk for developing mental health concerns or those experiencing mild concerns, prevention or early intervention resources, which may include group intervention (support or treatment groups) or low-intensity individualized supports (e.g., Check-In Check-Out). Tier 3 (indicated or intensive mental health treatment), provides students with mental health concerns causing moderate to severe impairment in functioning with intensive mental health treatment (e.g., individual or family therapy, individualized education program).

Across MTSS, an array of specific programs and strategies exist that aim to prevent (Tier 1), intervene early with (Tier 2), and treat (Tier 3) a range of internalizing and externalizing problems such as anxiety, depression, trauma, attention and other executive functioning problems, and conduct difficulties. The evidence base on specific SMH interventions has grown over the past few decades (e.g., Arora et al., 2019; Farahnaz et al., 2011; O’Mara \& Lind, 2013), with many interventions having well-established evidence for effectiveness (Fazel et al., 2014). One factor that may impact implementation of multi-tiered evidence-based services, but has not been explicitly studied, is the multidisciplinarity 
(number of different types of professionals) of the $\mathrm{SMH}$ team.

\section{SMH Teams and Multidisciplinarity}

There is not general consensus about the ideal focus and/or composition of SMH teams. As described in the literature, SMH teams include special education pre-referral or intervention teams (Iachini et al., 2013) and grade level-specific, school-wide, or district-wide student mental health services and support teams. One of the earliest and most widespread applications of teaming in schools were "problem-solving" teams with the goal of reducing inappropriate special education referrals (Rosenfield et al., 2018). Contrarily, in some communities, any staffing that goes beyond that required by special education programming may be considered "excessive" and not the responsibility of the education sector (Hoover \& Bostic, 2021). The NCSMH's recent best practice guide on SMH teaming (2020a) highlighted possible team members for SMH teams, including school health and behavioral health staff, teachers, facilities/operations representatives, administrators, students and caregivers, and school-based community health and behavioral health providers. Hoover et al. (2019) described ideal CSMHS as being:

built on a strong foundation of district and school professionals, including administrators, educators and specialized instructional support personnel (e.g., school psychologists, school social workers, school counselors, school nurses and other school health professionals), all in strategic partnership with students and families, as well as community health and mental health partners. (p. 13).

Similarly, many have characterized high-quality SMH teams as being composed of multiple partners, professionals, and stakeholders at the district and school level (Mellin et al., 2011; Nastasi, 2004; Sugai et al., 2014; Weist et al., 2001).

Despite anecdotal evidence of the importance of multidisciplinary SMH teams (Walker, 2018), the literature is limited about the impact of SMH team multidisciplinarity on service provision and student outcomes. There are a few studies that provide preliminary guidance about the effect of teaming best practices on service provision in schools. For example, Anderson-Butcher and Ashton (2004) found that collaborative services and teaming are associated with broader scope and greater access to services. Research also suggests that more diverse team structures are desirable as they provide more holistic dialogue and bring diverse experiences and expertise (Etscheidt \& Knesting, 2007; Iachini et al., 2013; Mellin, 2009). Having a designated team leader, a clear purpose, and established processes and procedures are also described as beneficial structural characteristics (Iachini et al., 2013). Finally, hospitable conditions for effective teamwork have been proposed as best practices, including: (1) having a physical space to meet, (2) prioritizing time to collaborate, (3) positive relationships between collaborators, and (4) a precedent of positive collaboration experiences (Mellin et al., 2011).

Although much of the guidance for SMH teamwork is preliminary and based on anecdotal evidence (Mellin, 2009), initial studies have identified common competencies (Ball et al., 2010), proposed optimal teaming processes demonstrated by exemplar cases (Phillippo \& Stone, 2006), and created a conceptual model for interdisciplinary collaboration (Mellin, 2009). Because teamwork in SMH is not often systematically measured, little is known about SMH teaming structures and processes, the extent to which these teams deliver services and improve outcomes (Mellin, 2009), and the conditions that promote effective collaboration (Borg \& Pålshaugen, 2019; Mellin et al., 2011).

\section{Community Providers on SMH Teams}

Partnership with community behavioral health providers is increasingly common in SMH teaming. This is due in part to models and best practices that indicate community partnership as a core feature in CSMHS (Barrett et al., 2013; Connors et al., 2016). Such partnerships may be with hospitals, community clinics, and social service organizations whose employees provide SMH services along with schoolemployed professionals (e.g., school social workers, school psychologists, school counselors, school nurses, administrators). Partnerships between schools and community providers can fill gaps in expertise, provide greater access to SMH services for their student population, and improve connection to families and the broader community (Hoover \& Bostic, 2021). However, most of these purported benefits are based on theory and anecdotal accounts, as rigorous research examining the direct impact of these partnerships on service implementation and outcomes has not been conducted.

Despite the potential benefits, school-community partnerships may introduce several hurdles, including community partners working in a "siloed" way with limited attention to school procedures and priorities, concerns about privacy, distrust and turf issues, and differences in diagnostic systems, goals, and professional orientations (Mellin \& Weist, 2011; Villarreal \& Castro-Villarreal, 2016). Despite the previously stated recommendations for school-community partnerships, it is not known how the inclusion of community providers on SMH teams actually affects service delivery and if there is any added benefit (Mellin et al., 2016). In one of the few studies to examine SMH Team Multidisciplinarity (TM), Iachini et al. (2013) analyzed data on 41 school-based service-delivery teams from 19 schools and found a range 
of 1 to 11 roles present in each team, with an average of 5.7 roles per team. Nearly 70 percent of teams had representation from outside of the school. However, the impact of having community partners on service delivery or other student outcomes was not examined. A more robust examination of schools nationally is needed to answer questions about SMH TM, including the degree to which multidisciplinarity and/or representation of community partners impacts SMH service delivery, and whether this relationship differs based on school and/or student characteristics.

\section{The Current Study}

This study occurred in the context of an initiative led by the NCSMH to improve understanding of the landscape of mental health in schools across the United States. As part of that effort, in 2016, the NCSMH developed and launched a national SMH census, the School Mental Health Profile (SMH Profile; Hoover et al., 2016). The current study uses secondary data to: (1) describe who serves on SMH teams and; (2) examine how the professional composition of a team impacts availability of MTSS across each tier (Tier 1, 2, and 3) and provision of services to students with different types of mental health needs (e.g., attention, anxiety, conduct problems). Specific research questions are: (1) What is the team size, team multidisciplinarity (TM) (i.e., number of different professions represented on a team) and presence of community providers among SMH teams, and how does this vary by location, school size, and school type (i.e., elementary, middle, high)? (2) What is the association between $\mathrm{TM}$ and rates of SMH service provision across tiers and for specific problem areas (i.e., anxiety, attention, depression, conduct, and trauma)? (3) What is the association between the presence of a team member from the community (i.e., non-school employed) and rates of service provision across tiers and problem areas?

\section{Method}

\section{Participants}

Participants were school teams who completed the School Mental Health (SMH) Profile (Hoover et al., 2016; additional details in measures section) on The School Health Assessment and Performance Evaluation System (SHAPE; https:// www.theshapesystem.com/). The SHAPE System is a public-access, web-based platform that offers schools, districts, and states/territories a workspace and targeted resources to support SMH quality improvement. The SHAPE system is promoted by the NCSMH through social media, conferences, and professional networks, but the website and the SMH profile are free and available to anyone. There is no compensation for completing the SMH Profile. SHAPE was developed by the NCSMH, in partnership with the field, to increase the quality and sustainability of CSMHS.

To standardize responses for the purpose of this study, only school team data were included to provide a summary of building-level teams and their resources. Individual schools that both completed the SMH Profile on the SHAPE System between 2016 and 2019 and reported data for study variables (i.e., team size) were included in this sample. Data from these 386 schools are presented below. There was school representation from every federal region with Region 1 (CT, MA, ME, NH, VT, RI), Region 4 (AL, FL, GA, MS, KY, TN, SC, NC) and Region 5 (IL, IN, MI, $\mathrm{OH}, \mathrm{WI})$ making up the majority of the sample $(62.5 \%)$. A large portion of the schools were in suburban areas (40.2\%) and many were elementary schools (57.5\%). Average student enrollment was 648 students per school and ranged from 6 to 3055 students served. Most schools that reported their Title 1 status received Title 1 funds $(82.3 \%)$ and about a third of the schools were predominantly (75\% or more) White (32\%). See additional school demographic characteristics in Table 1.

\section{Procedures}

Data were exported from the online database to use for secondary data analysis. Individual school building-level data were selected for analysis. Data were examined for errors and cleaned. SMH Profile users were notified that information entered may be compiled in aggregate to describe and examine patterns of SMH features. Use of these data was reviewed and deemed exempt by the University of Maryland Human Research Protections Office Institutional Review Board.

\section{Measures}

\section{School Mental Health (SMH) Profile}

The SMH Profile is an online assessment tool, available on SHAPE, to assist schools and districts in documenting the structure and operations of their CSMHS (Hoover et al., 2016). The SMH Profile was developed in 2016 by the NCSMH in cooperative agreement with the U.S. Health and Human Services, Health Resources and Services Administration, Maternal and Child Health Bureau. The SMH Profile was developed through a multi-stage process that engaged SMH experts and diverse stakeholders. The SMH Profile measures key features of CSMHS including multi-tiered services and supports provided, students served, staffing and use of data-driven decision making (Hoover et al., 2016). The goal of the SMH Profile is to provide a tool for schools and school districts to document the structure and operations 
Table 1 Study variable means and standard deviations by school demographics

\begin{tabular}{|c|c|c|c|c|}
\hline Variables & Total $n$ & $\begin{array}{l}\text { Team size (\# of } \\
\text { team members) }\end{array}$ & $\begin{array}{l}\text { Team multidisciplinarity } \\
\text { (\# of different disciplines) }\end{array}$ & $\begin{array}{l}\% \text { with } \\
\text { community } \\
\text { Partners }\end{array}$ \\
\hline \multicolumn{5}{|l|}{ Overall (with /median) } \\
\hline & & $11.75(6.50) / 11$ & $9.41(3.64) / 9$ & 45.85 \\
\hline \multicolumn{5}{|l|}{ Location } \\
\hline City & 97 & $11.69(6.37)$ & $9.46(4.09)$ & 38.14 \\
\hline Suburb & 155 & $12.00(6.51)$ & $9.50(3.45)$ & 50.32 \\
\hline Town & 42 & $13.17(8.02)$ & $9.68(4.40)$ & 50.00 \\
\hline Rural & 92 & $11.75(6.50)$ & $8.80(3.77)$ & 44.57 \\
\hline \multicolumn{5}{|l|}{ School Size } \\
\hline Small school (enrollment < 574) & 204 & $10.42(6.02)^{\mathrm{c}}$ & $9.53(3.81)$ & $50.98^{\mathrm{a}}$ \\
\hline Large school & 182 & $13.23(6.72)$ & $9.17(3.82)$ & 40.11 \\
\hline \multicolumn{5}{|l|}{ School Level } \\
\hline Elementary & 222 & $10.49(5.66)^{\mathrm{c}}$ & $9.09(3.63)$ & 42.79 \\
\hline Middle & 69 & $12.92(7.20)$ & $9.82(4.07)$ & 52.17 \\
\hline High School & 95 & $11.75(6.50)$ & $9.35(3.82)$ & 48.42 \\
\hline \multicolumn{5}{|l|}{ Title 1 Status } \\
\hline Title one status & 247 & $11.14(6.30)$ & $9.21(3.58)$ & 42.96 \\
\hline No title one status & 53 & $11.97(6.68)$ & $9.10(2.94)$ & 41.51 \\
\hline \multicolumn{5}{|l|}{ Racial Demographics } \\
\hline Predominantly White $(\geq 75 \%)$ & 123 & $12.25(6.56)$ & $9.26(3.55)$ & $59.35^{\mathrm{b}}$ \\
\hline Not predominately White $(<75 \%)$ & 259 & $11.55(6.50)$ & $9.50(3.68)$ & 39.77 \\
\hline
\end{tabular}

of their CSMHS and to collectively provide a census of the landscape of SMH nationally.

In the SMH Profile, schools and school districts report: (1) their mental health data collection and use; (2) staffing available to provide services across MTSS for students and (3) services and supports provided within MTSS for diverse mental health concerns. The profile is estimated to take 1-2 $\mathrm{h}$ to complete when completed as a team, which is recommended. The current study used a subset of MTSS staffing and services and supports variables described in detail below.

Team Size and Multidisciplinarity Within the staffing section of the SMH Profile, schools report on (1) what types of professionals they have on their team from a list of 32 roles (e.g., school psychologist, school counselor, school administrator), in yes/no response format; (2) how many people in each role they had on their team (entered as a numerical value); (3) whether each role was school employed (yes/no) or community employed (yes/no); and (4) the full time equivalent (FTE) for all staff in that role (entered as a numerical value). This staffing information was recoded for the purposes of this study. Total Team
Size is a sum of the total number of team members across all 32 possible roles, representing the total number (continuous variable) of team members on the SMH team. Team Multidisciplinarity (TM) is a sum of the total number of distinct roles from the list of 32 possible roles, representing the total number (continuous variable) of unique roles on the team. The presence of a community employed provider is a dichotomous variable representing whether the school had one or more community providers (yes $=1 /$ no $=0$ ).

Service Provision. Schools reported whether they provided services for five mental health domains at each of the tiers (Tiers 1, 2, and 3) using a dichotomous variable (yes/no) for each mental health domain at each tier. For each mental health domain, a Service Provision variable was created by converting the dichotomous Tier 1,2 , and 3 scores into a new variable with values from 0 to $3(0=$ no services provided, $1=$ services from 1 of the 3 tiers provided, $2=$ services from 2 of the 3 tiers provided, and $3=$ services provided at all 3 tiers. The five mental health domains included: (1) Anxiety/Nervousness/Phobias, (2) Attention/Concentration/Hyperactivity problems, (3) Oppositional or Conduct Problems/Anger 
Management, (4) Depression/Sadness/Suicide, and (5) Trauma/PTSD/Abuse/Neglect/Ex posure to Violence.

School Demographic Variables School demographic variables (i.e., region, location, school level, student racial/ethnic composition, Title 1 status) were reported from the National Center for Education Statistics (NCES) database for the 2017-2018 school year (NCES, 2019) and merged with our dataset using the NCES school ID. Detailed information on NCES data collection and scoring are described below.

Region. Categorical variables were created using the school's state location to determine its membership in a "standard federal region" as denoted by the Office of Management and Budget. Governmental agencies, including the Department of Education, use this to divide the country into 10 regions.

Location. School location was collapsed from 12 categories (i.e., large city, small city, mid-size suburb, small suburb) into 4 categories (city, suburb, town, rural).

School Level. Schools denoted as Elementary (K-4), Middle (5-8), and High School (includes 12th grade) in the NCES databases were included in this analysis.

Enrollment. NCES collected information on student enrollment in each school and provided a numerical value for total number of students enrolled.

Title 1 Status. A dichotomous variable indicating whether a school had Title 1 status or not. Title 1 status indicates whether a school received federal funds to support underserved children in meeting state academic standards. Schools qualify for Title 1 if $40 \%$ or more of students come from low-income families.

Racial demographics. NCES collected information on the number of students within a school identifying with several race and ethnicity categories that were then divided by the total enrollment number to create percentages. For analytic purposes a dichotomous variable was created to indicate whether the school population was greater than or equal to $75 \%$ ("predominantly") White and mimicked categorical variables used in a recent report from NCES. In 2021, NCES reported, almost half (47\%) of White students were enrolled in public schools that were predominantly White (i.e., $75 \%$ or more of enrollment was White) in 2018 (Irwin et al., 2021). Additionally, about a third (31\%) of students attended schools where minority students were $75 \%$ of the student population in the same year (Irwin et al., 2021). Using 75\% as the cutoff allowed for the dichotomous variable to reflect a common occurrence in public school enrollment where a large proportion of schools are mostly white or mostly minority students.

\section{Data Analysis}

RQ 1 Does Team Multidisciplinarity (TM) and presence of community providers vary by school location, school size and school type?

Differences in the presence of a community provider by school location, school size and school type were investigated using chi-square test of independence. As TM was a continuous variable, Analysis of Variance tests (ANOVAs) were used to compare means across the three independent variables (location, school size, and school level).

RQ 2 Is Team Multidisciplinarity (TM) related to degree of service provision?

A linear regression was used to assess the contribution of $\mathrm{TM}$ and Total Team Size on presence of service provision for presenting concerns across tiers. Assumptions for regression analyses were examined, including a linear relationship, normality, independence, and homoscedasticity using scatterplots of the variables' relations and their variances, as well as the Durbin-Watson statistic and histograms. Total Team Size was examined as a possible covariate to include in the regression models via bivariate correlations with Service Provision. The correlation was significant, and this variable was used as a covariate. Total Team Size was entered in the first block, and TM was entered in the second block.

The relation between TM and service provision was further examined by using a median split to separate the data into two groups: Low TM and High TM ( $>9$ different professional roles). The percentage of teams endorsing services at each tier were also provided to increase understanding of the relation between the two variables.

RQ 3 What is the association between the presence of a community provider and service provision?

Multivariate analysis of covariance (MANCOVA) was used to examine group differences between teams that did and did not have a community provider on their SMH team, while controlling for team size. Means, standard deviations and eta squared were calculated to assess contribution of community providers to differences in service provision across groups and provide data on descriptive differences, by service level, for each set of mental health problems. Percentage of teams endorsing services at each tier were provided for further description. 
Table 2 Effect of team size and team multidisciplinarity (TM) on service provision for student presenting concerns

\begin{tabular}{|c|c|c|c|c|c|c|c|c|c|c|}
\hline \multirow[t]{2}{*}{ Covariates } & \multicolumn{2}{|l|}{ Anxiety } & \multicolumn{2}{|l|}{ Attention } & \multicolumn{2}{|l|}{ Conduct } & \multicolumn{2}{|l|}{ Depression } & \multicolumn{2}{|l|}{ Trauma } \\
\hline & $\begin{array}{l}\text { Model } 1 \\
\text { (Covariates) }\end{array}$ & $\begin{array}{l}\text { Model } 2 \\
(+\mathrm{TM})\end{array}$ & $\begin{array}{l}\text { Model } 1 \\
\text { (Covariates) }\end{array}$ & $\begin{array}{l}\text { Model } 2 \\
(+\mathrm{TM})\end{array}$ & $\begin{array}{l}\text { Model } 1 \\
\text { (Covariates) }\end{array}$ & $\begin{array}{l}\text { Model } 2 \\
(+\mathrm{TM})\end{array}$ & $\begin{array}{l}\text { Model } 1 \\
\text { (Covariates) }\end{array}$ & $\begin{array}{l}\text { Model } 2 \\
(+\mathrm{TM})\end{array}$ & $\begin{array}{l}\text { Model } 1 \\
\text { (Covariates) }\end{array}$ & $\begin{array}{l}\text { Model } 2 \\
(+\mathrm{TM})\end{array}$ \\
\hline Total Team Size & $.22 * *$ & $.19^{* *}$ & $-.19 * *$ & -.11 & $.16^{* *}$ & .09 & $.18^{* *}$ & $.12 *$ & $.16^{* *}$ & .10 \\
\hline $\mathrm{TM}$ & & .06 & & $.16^{* *}$ & & $.13^{*}$ & & $.12 *$ & & $.13^{*}$ \\
\hline$R^{2}$ & .05 & .05 & .04 & .06 & .02 & .04 & .03 & .04 & .03 & .04 \\
\hline
\end{tabular}

$* p<.05 ; * * p<.01$

\section{Results}

RQ 1 Does Team Multidisciplinarity (TM) and presence of community providers vary by school location, school size and school type?

Results for research question 1 are reported in Table 1. On average, $9.41(\mathrm{SD}=3.64)$ different professional roles were represented on SMH teams with a range between 1 and 19 different roles. School administrators, school counselors, school psychologists, nurses, and social workers were commonly endorsed team members (more details provided in the online resource). Community providers served on SMH teams in 177 schools (46\%), with community behavioral health workers being the most common. On average, smaller schools endorsed having a community provider on the SMH team more frequently than larger schools $\left(50.98 \%\right.$ vs. $\left.40.11 \% ; X^{2}(1, N=386)=4.58, p<0.05\right)$ but smaller schools had significantly smaller teams overall $(F(1,384)=18.73, p<0.001)$. Elementary schools had significantly smaller teams than middle and high schools $(F(2,383)=10.53, p<0.001)$. Schools serving predominantly White students reported having a community provider more frequently than schools that were not predominantly White $\left(X^{2}(1, N=382)=12.87, p<0.001\right)$. There were no significant differences in TM by location, school size, school level, Title 1 status, or racial demographics. There were also no significant differences in the presence of a community provider by location, school level, or Title 1 status. Additional information on types of roles represented on SMH teams is available in Online Resource 1.

RQ 2 Is Team Multidisciplinarity (TM) related to degree of service provision?

Results for research question 2 are reported in Tables 2 and 3. Results indicated that TM was significantly related to the amount of service provision schools provided in all mental health domains assessed except for anxiety (1-2\% of variance explained; Table 2). In addition, schools with High TM reported service provision at each tier at higher
Table 3 Descriptive Data on Service Provision for School Mental Health Teams with High or Low Team Multidisciplinarity (TM) across Tiers

\begin{tabular}{|c|c|c|}
\hline Type of service provision & Low TM $(\%)^{\mathrm{a}}$ & $\operatorname{High}$ TM $(\%)^{\mathrm{b}}$ \\
\hline Anxiety $(M, \mathrm{SD})$ & $1.20,1.09$ & $1.58,1.21$ \\
\hline Tier 1 & 38.30 & 51.10 \\
\hline Tier 2 & 40.00 & 55.40 \\
\hline Tier 3 & 42.00 & 51.10 \\
\hline No Services & 5.28 & 3.43 \\
\hline Attention $(M, \mathrm{SD})$ & $1.27,1.08$ & $1.69,1.15$ \\
\hline Tier 1 & 40.00 & 56.00 \\
\hline Tier 2 & 45.60 & 59.10 \\
\hline Tier 3 & 42.00 & 53.8 \\
\hline No Services & 4.49 & 1.06 \\
\hline Conduct $(M, \mathrm{SD})$ & $1.38,1.15$ & $1.67,1.18$ \\
\hline Tier 1 & 45.60 & 52.2 \\
\hline Tier 2 & 45.10 & 57.00 \\
\hline Tier 3 & 47.70 & 58.10 \\
\hline No Services & 3.17 & 2.37 \\
\hline Depression $(M, \mathrm{SD})$ & $1.29,1.15$ & $1.66,1.20$ \\
\hline Tier 1 & 44.00 & 51.60 \\
\hline Tier 2 & 36.80 & 53.80 \\
\hline Tier 3 & 48.20 & 59.10 \\
\hline No Services & 4.22 & 1.58 \\
\hline Trauma $(M, \mathrm{SD})$ & $1.07,1.07$ & $1.40,1.17$ \\
\hline Tier 1 & 30.60 & 40.30 \\
\hline Tier 2 & 33.20 & 43.50 \\
\hline Tier 3 & 43.00 & 56.00 \\
\hline No Services & 4.49 & 2.64 \\
\hline
\end{tabular}

Bolded rows indicate $\approx 15 \%$ greater rate of reported service provision in schools with high TM

${ }^{\mathrm{a}}$ Results indicate the percent (\%) of Low TM schools (fewer than nine distinct professional roles) reporting service provision for each category

${ }^{\mathrm{b}}$ Results indicate percent (\%) of High TM schools ( 9 or more distinct professional roles) reporting service provision for each category

rates than did schools with low TM, consistent across all tiers and service types (Table 3 ). Further, descriptive data (Table 3) suggested that provision of Tier 2 services and 
supports were more frequently endorsed by schools who also endorsed higher TM. As shown in Table 3, approximately 15\% more schools in the High TM group reported having Tier 2 services. The difference in endorsement was also present at other service levels (i.e., Tier 1 Attention) yet less consistently than Tier 2 .

\section{Post Hoc Analyses}

Chi-Square tests confirmed a significantly higher percentage of Tier 2 services reported among schools with high TM. Specifically, schools with high TM were more likely than schools with low TM to have services at Tier 2 for anxiety $\left(X^{2}(1, N=277)=15.54, p<0.001\right)$, attention $\left(X^{2}(1, N=277)=14.70, p<0.001\right)$, conduct problems $\left(X^{2}(1, N=277)=10.91, p<0.01\right)$, depression $\left(X^{2}(1, N=277)=13.95, p<0.001\right)$ and trauma $\left(X^{2}(1\right.$, $N=277)=10.75, p<0.01)$.

RQ 3 What is the association between the presence of a community provider and service provision?

MANCOVA results indicated a significant difference in service provision reported by schools based on whether or not they reported having a community provider on their SMH team, when controlling for team size $(F(5$, $379)=3.49, p<0.01$; Wilk's $\Lambda=0.956$, partial $\left.\eta^{2}=0.04\right)$. Having a community provider explained $1-4 \%$ of the variance in service provision when controlling for team size (Table 4). Univariate statistics suggest the relation is significant for services related to depression and trauma, with the presence of a community provider accounting for $1 \%$ and $4 \%$ of the variance in service provision, respectively. Descriptive data suggested Tier 2 services and supports were more frequently endorsed when a community provider was present on the SMH team, as noted by the $15 \%$ increase in the endorsement of services at Tier 2 for schools with community providers (Table 4).

\section{Post Hoc Analyses}

Chi-Square tests confirmed a significant difference in the availability of Tier 2 services with the presence of a community provider on the SMH team. Specifically, schools with teams with a community provider were more likely than schools with teams without a community provider to endorse service provisions at Tier 2 for anxiety $\left(X^{2}(1, N=454)=38.48, p<0.001\right)$, attention $\left(X^{2}(1, N=454)=44.77, p<0.001\right)$, conduct problems $\left(X^{2}(1, N=454)=38.72, p<0.001\right)$, depression $\left(X^{2}(1, N=454)=29.61, p<0.001\right)$ and trauma $\left(X^{2}(1\right.$, $N=454)=48.25, p<0.001)$.
Table 4 MANCOVA results and descriptive data on service provision for school mental health teams with and without a community employed (CE) team member accounting for overall team size

\begin{tabular}{|c|c|c|c|c|}
\hline Measure & $\begin{array}{l}\text { No CE team } \\
\text { member }^{\mathrm{a}}(\%)\end{array}$ & $\begin{array}{l}\text { CE team } \\
\text { member } \\
(\%)\end{array}$ & $F(1,384)$ & $\eta^{2}$ \\
\hline Anxiety $(M, S E)$ & $1.31, .08$ & $1.51, .09$ & 2.86 & .01 \\
\hline Tier 1 & 40.70 & 50.00 & & \\
\hline Tier 2 & 41.60 & $\mathbf{5 6 . 0 0}$ & & \\
\hline Tier 3 & 42.10 & 53.10 & & \\
\hline No Services & 7.00 & 1.55 & & \\
\hline Attention $(M, \mathrm{SE})$ & $1.39, .08$ & $1.60, .08$ & 3.18 & .01 \\
\hline Tier 1 & 45.00 & 51.40 & & \\
\hline Tier 2 & 45.50 & 60.50 & & \\
\hline Tier 3 & 43.50 & 54.20 & & \\
\hline No Services & 4.15 & 1.30 & & \\
\hline Conduct $(M, \mathrm{SE})$ & $1.47, .08$ & $1.63, .09$ & 1.74 & .01 \\
\hline Tier 1 & 48.30 & 50.30 & & \\
\hline Tier 2 & 45.00 & 59.3 & & \\
\hline Tier 3 & 48.80 & 58.80 & & \\
\hline No Services & 3.63 & 1.81 & & \\
\hline Depression $(M, \mathrm{SE})$ & $1.36, .08$ & $1.62, .09$ & $4.69 *$ & .01 \\
\hline Tier 1 & 41.10 & 56.00 & & \\
\hline Tier 2 & 40.70 & 52.00 & & \\
\hline Tier 3 & 48.80 & 60.50 & & \\
\hline No Services & 4.66 & 1.04 & & \\
\hline Trauma $(M, \mathrm{SE})$ & $1.04, .08$ & $1.48, .08$ & $14.56 * *$ & .04 \\
\hline Tier 1 & 30.10 & 42.40 & & \\
\hline Tier2 & 30.00 & 49.20 & & \\
\hline Tier 3 & 40.00 & 62.00 & & \\
\hline No Services & 6.48 & .52 & & \\
\hline
\end{tabular}

Bolded cells show $\approx 15 \%$ increase in the percentage of schools reporting services in an area

${ }^{\mathrm{a}} N=209$, results reported as the percent (\%) of schools with no CE team members indicating service provision for each category

${ }^{\mathrm{b}} N=177$, results reported as the percent (\%) of schools with a CE team member indicating service provision for each category

$* p<.05 . * * p<.001$

\section{Discussion}

SMH best practice guidelines emphasize the importance of community providers and multidisciplinary teams (Connors et al., 2016; Hoover et al., 2019), yet there have been limited empirical investigations to support these recommendations (Iachini et al., 2013; Mellin et al., 2016). Results from this study furthered our understanding of SMH teams in several areas. Firstly, results provided information about the association of school demographics with TM and the presence of community providers. There were reported differences between the presence of community providers by school size and racial demographic of schools; these associations 
were not replicated with TM. Additionally, results indicated the presence of multidisciplinary partners on $\mathrm{SMH}$ teams, including community providers, was associated with reported availability of SMH services in the school after controlling for team size (which was, not surprisingly, associated with availability of SMH services). This relation explained a small amount of the difference in services between high TM and low TM schools. High TM was associated with service provision; services related to attention difficulties showed the strongest association. Finally, having a community provider on the SMH team was associated with the endorsement of service provisions, particularly depression and trauma services. Overall, the effect size was small for our main research questions. Descriptive data suggested Tier 2 services particularly benefited from more TM and the presence of community providers. Further post hoc analyses indicated the difference in Tier 2 services was statistically significant.

Descriptive data highlighted the variability in the presence of community providers by school demographic variables. Reporters from smaller schools endorsed the presence of community providers at a higher rate than larger schools. This finding is consistent with Foster et al. (2005) where small schools also had a higher percentage of community providers than larger schools. Reporters from schools that were predominately White endorsed the presence of a community provider at a higher frequency than schools with that were not predominately White. Interestingly, TM did not show similar differences with respect to school size or racial demographics. A possible explanation is that smaller schools need to contract with outside agencies to create their SMH teams because they have less staffing available through the school or district; teams may be as diverse in role representation but require the presence of a community provider to accomplish TM. Additional support for this explanation was found in the Foster et al. (2005) report where a smaller percentage of the mental health staff was school-based in small schools vs larger schools (11.9\% vs $15.6 \%$ ).

The difference in the presence of a community provider by the racial demographics of the student body may be explained by a difference in resources for mental health programming. White students typically attend schools with more resources (Mickelson, 2003) therefore a possible explanation is that schools with more racial diversity have fewer funds available to supplement their services with outside providers. Also, funding structures make it difficult for providers to be reimbursed for the continuum of school mental health services (Hoover \& Bostic, 2021), which would be a barrier that could disproportionately impact low-income, minority students who rely on state-funded insurances for mental health needs.

Stigma may also play a role. Historically, racial/ethnic minorities underutilize mental health services in the community. This may be due to a combination of factors such as language barriers, cultural differences, systemic racism, low availability of providers, and a distrust of systems. The difference in the presence of a community provider may reflect comfort in engaging with mental health systems. The lack of difference in actual school teams or size by race and Title 1 status may support this conclusion as well. Within the school, children appear to have access to the same amount of mental health support staff, and this may be helped by funding provided by Title 1 to reduce disparities in education. Yet, there is still a difference in how schools engage external partners and acquire additional resources to support students.

Leaders in CSMH have long recommended that schools form teams with high multidisciplinarity (Hoover \& Bostic, 2021; Hoover et al., 2019). These recommendations were largely based on theory and practical experience suggesting the effectiveness of multidisciplinary teams in their ability to fill gaps in expertise, provide greater access to SMH services for their student population, and improve their connection to the broader community and families (Weist, 1997). Previous empirical studies were limited by geographic region (Bates et al., 2019) and did not draw conclusions about the relation between teams and services (Iachini et al., 2013). The results of this study linked team multidisciplinarity to service provisions, within a national sample, that included diverse school levels, student populations, urbanicity, and geographic regions.

Previous literature would suggest the relation between team multidisciplinarity and service provision was the result of more holistic dialogue between team members and diverse experiences and expertise on the team (Etscheidt \& Knesting, 2007; Iachini et al., 2013; Mellin, 2009), which expanded the types of interventions and the availability of service provisions across tiers. Having team members from a broader array of disciplines may allow individuals to use their expertise to fill gaps in services. Tier 2 services seemed to benefit the most from having a diverse team composition. This finding warrants additional research to confirm through replication and further study about the reason for this association. In the current study, the endorsement of services was related to greater TM, above and beyond just an increase in team size. One possible explanation is targeted hiring decisions. Greater TM among schools with more Tier 2 services could be associated with hiring decisions, whereby schools add team members when they have an interest in filling their Tier 2 gaps. Seeking a diversity of expertise would likely support service organization and expanded provision at this tier.

The added value of community providers on SMH teams was also supported by the results of this study. Previous literature highlighted the recommendation to engage community providers in SMH teams, (Barrett et al., 2013; Weist, 
1997) and the practice was endorsed as a best practice for SMH teaming (Hoover et al., 2019). Having a community provider, similar to having a multidisciplinary SMH team, was proposed to be a mechanism for increasing availability of services to its student body (Weist, 1997). Having a community provider on the SMH team was associated with the endorsement of service provision in several mental health domains in the current sample, with trauma services benefiting most significantly from the presence of a community provider. This relation could be the result of a current zeitgeist focusing on trauma-informed care with additional funding and resources being dedicated to improving services in this area (Stratford et al., 2020). This finding may also reflect targeted training and expertise in trauma-based services and/or more severe mental health concerns being treated by community-based providers.

Current findings suggest that while partnering with a community provider is commonly promoted, it is not as commonly practiced as prior studies would suggest. Compared to Iachini et al. (2013) finding that $70 \%$ of schools reported the presence of a community provider, only $48 \%$ of schools in the current sample reported including community providers. This under-utilization of community providers may be the result of continuing barriers to forming community partnerships (Mellin \& Weist, 2011; Villarreal \& Castro-Villarreal, 2016). Like team multidisciplinarity, having a community provider was also significantly associated with the endorsement of Tier 2 services. The addition of community providers may expand and complement $\mathrm{SMH}$ team's expertise allowing the team to offer a broader array of services at this tier (Hoover \& Bostic, 2021).

The posthoc analyses highlighted the association between Tier 2 service provision and TM, as well as Tier 2 service provision and the presence of community providers. Both anxiety and attention service provisions were associated with higher TM and the presence of a community provider. Depression service provision was associated with higher TM at Tier 2. Conduct and trauma service provisions at Tier 2 were also associated with the presence of a community provider. Briefly above, we noted this could be the result of targeted hiring decisions to fill gaps in services at Tier 2. Tier 2 services are early intervention services such as low-intensity classroom-based supports (e.g., check-in/check-out), small group interventions of students with similar needs (e.g., CBITS), or brief individualized interventions (e.g., motivational interviewing). Best practices recommend that students should be screened into tier 2 services, that there should be progress monitoring, and that data-driven decision to move students across tiers (NCSMH, 2020b). The need for screening and data-monitoring for individual students may explain the association between Tier 2 and a more diverse team. School counselors, school administrators, school psychologists, and school nurses were commonly endorsed SMH team members (Online Resource 1) yet the core training components for their professional programs are not centered on providing ongoing mental health services to students, which could prompt adding team members with more specialized expertise, like community partners, when adding a Tier 2 intervention.

\section{Implications}

\section{Practice}

The results of the study indicated that schools with greater team multidisciplinarity also frequently endorsed more services in their schools. This information may be helpful to schools with limited resources that may opt to prioritize SMH team multidisciplinarity, as opposed to size, related to resource constraints. This research also supports efforts to reduce the barriers to creating community partnerships at the school and district level so more schools can benefit from the presence of school-community provider partnerships. Additionally, the difference in the presence of a community provider by racial demographics may be helpful information when districts and states disaggregate their data to better understand how they can support schools in improving CSMHS to meet the needs of diverse communities.

\section{Research}

This study provides preliminary empirical evidence of a relation between SMH team composition and the endorsement of services at more tiers by schools. Further research is needed to investigate the relation between SMH team composition and the quality of service provision not just the quantity. This will likely require strong partnerships with mental health providers in buildings to institute regular progress monitoring tools so team composition data can be linked with student outcomes. NCSMH provides resources for CSMHS interested in assessing and improving their documentation of the impact of services that may be useful. Additionally, advances in implementation science detail strategies to implement evidence-based practices in schools and promote a high level of care. Also, investigating the relation between type of role (e.g., school social worker, school psychologist, counselor, community mental health provider) and service provisions is needed. As is detangling whether it is multidisciplinarity (e.g.., I need a school psychologist and a social worker) or unique skills and training (e.g., 2 social workers with different specialties) that contributes to the service provision outcomes. Although beyond the scope of this study, an important question remains for the field: What is the impact of team composition on student outcomes? Further exploration of the impact of multidisciplinarity and community partnership on, not only service 
array, but also on student outcomes can shape guidance related to creating efficient and effective SMH teams.

\section{Limitations}

This study makes several contributions to the literature by providing empirical support for best practices in SMH teaming. However, some limitations include: (1) the cross-sectional nature of the study, (2) the lack of information about the quality or type of services provided, and (3) the use of self-reported data from a self-selected sample. Available data only indicated whether services were available at each tier and could be augmented in future studies by inquiring about specific service targets and modalities, and examining impact on student outcomes. Additionally, teams who completed the SMH Profile voluntarily accessed a platform to catalog their school-based services so the sample may be skewed toward schools with school mental health teams or those actively engaging in quality improvement initiatives and may not be representative of SMH teams not currently interested in assessing, improving, or expanding their systems. Also, the measure was self-report therefore there may have been some subjectivity in the reporting. Future studies may use purposeful sampling techniques to address selection bias and add measures to triangulate findings and support conclusions. Finally, future longitudinal studies may examine shifts of teaming structure and staffing over time to further inform the role of team multidisciplinarity and community partnerships on service provisions.

\section{Conclusion}

Creating SMH teams with multidisciplinary stakeholders and community providers is often endorsed by researchers and policy makers. This study provided evidence of the potential importance of SMH team composition, including diversity of team membership and inclusion of community partners. In addition to advancing the empirical support for nationally endorsed teaming best practices (NCSMH, 2020a), findings from this study can inform SMH staffing decisions by recognizing the added value of having multiple disciplines and both school and community providers on SMH teams.

Supplementary Information The online version contains supplementary material available at https://doi.org/10.1007/s12310-021-09493-z.

Acknowledgment We would like the acknowledge the passing of our co-author Michael Kelly and his invaluable contribution to the field, both through his work and his support of his colleagues and trainees. He will be missed.

Funding This study was supported by Health Resources and Services Administration (HRSA; U61MC31885) and National Institute of Mental Health (NIMH; K08 MH116119).

\section{References}

Anderson-Butcher, D., \& Ashton, D. (2004). Innovative models of collaboration to serve children, youths, families, and communities. Children \& Schools, 26(1), 39-53. https://doi.org/10.1093/ cs/26.1.39

Arora, P. G., Collins, T. A., Dart, E. H., Hernández, S., Fetterman, H., \& Doll, B. (2019). Multi-tiered systems of support for schoolbased mental health: A systematic review of depression interventions. School Mental Health, 11(2), 240-264. https://doi.org/10. 1007/s12310-019-09314-4

Ball, A., Anderson-Butcher, D., Mellin, E. A., \& Green, J. H. (2010). A cross-walk of professional competencies involved in expanded school mental health: An exploratory study. School Mental Health, 2(3), 114-124. https://doi.org/10.1007/s12310-010-9039-0

Barrett, S., Eber, L., \& Weist, M. (2013). Advancing education effectiveness: Interconnecting school mental health and school-wide positive behavior support. OSEP Center for Positive Behavioural Interventions and Supports. https://doi.org/10.1007/ s10488-008-0182-y

Bastian, K. C., Akos, P., Domina, T., \& Griffard, M. (2019). Understanding the allocation of student support personnel in public schools. AERA Open, 5(4), 1-17. https://doi.org/10.1177/23328 58419890322

Bates, S. M., Mellin, E., Paluta, L. M., Anderson-Butcher, D., Vogeler, M., \& Sterling, K. (2019). Examining the influence of interprofessional team collaboration on student-level outcomes through school-community partnerships. Children and Schools, 41(2), 111-122. https://doi.org/10.1093/cs/cdz001

Borg, E., \& Pålshaugen, Ø. (2019). Promoting students' mental health: A study of inter-professional team collaboration functioning in Norwegian schools. School Mental Health, 11(3), 476-488. https://doi.org/10.1007/s12310-018-9289-9

Cappella, E., Frazier, S. L., Atkins, M. S., Schoenwald, S. K., \& Glisson, C. (2008). Enhancing schools' capacity to support children in poverty: An ecological model of school-based mental health services. Administration and Policy in Mental Health and Mental Health Services Research, 35(5), 395. https://doi.org/10.1007/ s10488-008-0182-y

Connors, E. H., Stephan, S. H., Lever, N., Ereshefsky, S., Mosby, A., \& Bohnenkamp, J. (2016). A national initiative to advance school mental health performance measurement in the US. Advances in School Mental Health Promotion, 9(1), 50-69.

Duong, M. T., Bruns, E. J., Lee, K., Cox, S., Coifman, J., Mayworm, A. M., \& Lyon, A. R. (2020). Rates of mental health service utilization by children and adolescents in schools and other community service settings: A systematic review and meta-analysis. Administration and Policy in Mental Health and Mental Health Services. https://doi.org/10.1007/s10488-020-01080-9

Etscheidt, S., \& Knesting, K. (2007). A qualitative analysis of factors influencing the interpersonal dynamics of a prereferral team. School Psychology Quarterly, 22(2), 264-288. https://doi.org/10. 1037/1045-3830.22.2.264

Farahnaz, F. K., Grant, K. E., Polo, A. J., Duffy, S. N., \& DuBois, D. L. (2011). School-based mental health and behavioral programs for low-income, urban youth: A systematic and meta-analytic review. Clinical Psychology: Science and Practice, 18(4), 371-390. https://doi.org/10.1111/j.1468-2850.2011.01265.x

Fazel, M., Hoagwood, K., Stephan, S., \& Ford, T. (2014). Mental health interventions in schools in high-income countries. The Lancet Psychiatry, 1(5), 377-387. https://doi.org/10.1016/S22150366(14)70312-8

Foster, S., Rollefson, M., Doksum, T., Noonan, D., Robinson, G., \& Teich, J. (2005). School mental health services in the United States, 2002-2003. DHHS Pub. No. (SMA) 05-4068. Rockville, 
MD: Center for Mental Health Services, Substance Abuse and Mental Health Services Administration.

Hoagwood, K. E., Atkins, M., Kelleher, K., Peth-Pierce, R., Olin, S., Burns, B., Landsverk, J., \& Horwitz, S. M. (2018). Trends in children's mental health services research funding by the National Institute of Mental Health from 2005 to 2015: A 42\% reduction. Journal of the American Academy of Child \& Adolescent Psychiatry, 57(1), 10-13. https://doi.org/10.1016/j.jaac. 2017.09.433

Hoover, S., \& Bostic, J. (2021). Schools as a vital component of the child and adolescent mental health system. Psychiatric Services, 72(1), 37-48. https://doi.org/10.1176/appi.ps.201900575

Hoover, S., Lever, N., Connors, E., \& Bohnenkamp, J. (2016). School Mental Health Profile. University of Maryland, National Center for School Mental Health. Retrieved January 1, 2020, from https://www. theshapesystem.com/

Hoover, S., Lever, N., Sachdev, N., Bravo, N., Schlitt, J., Acosta Price, O., Sheriff, L., \& Cashman, J. (2019). Advancing comprehensive school mental health: Guidance from the field. Baltimore, MD: National Center for School Mental Health, University of Maryland School of Medicine.

Houtrow, A. J., Larson, K., Olson, L. M., Newacheck, P. W., \& Halfon, N. (2014). Changing trends of childhood disability, 20012011. Pediatrics, 134(3), 530-538. https://doi.org/10.1542/peds. 2014-0594

Iachini, A. L., Anderson-Butcher, D., \& Mellin, E. A. (2013). Exploring best practice teaming strategies among school-based teams: Implications for school mental health practice and research. Advances in School Mental Health Promotion, 6(2), 139-154. https://doi.org/10. 1080/1754730X.2013.784618

Irwin, V., Zhang, J., Wang, X., Hein, S., Wang, K., Roberts, A., York, C., Barmer, A., Bullock Mann, F., Dilig, R., \& Parker, S. (2021). Report on the Condition of Education 2021 (NCES 2021-144). U.S. Department of Education. Washington, DC: National Center for Education Statistics. Retrieved from https://nces.ed.gov/pubsearch/pubsinfo. asp?pubid $=2021144$.

Loades, M. E., Chatburn, E., Higson-Sweeney, N., Reynolds, S., Shafran, R., Brigden, A., Linney, C., McManus, M. N., Borwick, C., \& Crawley, E. (2020). Rapid systematic review: The impact of social isolation and loneliness on the mental health of children and adolescents in the context of COVID-19. Journal of the American Academy of Child \& Adolescent Psychiatry, 59(11), 1218-1239.e3. https://doi. org/10.1016/j.jaac.2020.05.009

Mellin, E. A. (2009). Unpacking interdisciplinary collaboration in expanded school mental health: A conceptual model for developing the evidence base. Advances in School Mental Health Promotion, 2(3), 4-14. https://doi.org/10.1080/1754730X.2009.9715706

Mellin, E. A., Anderson-Butcher, D., \& Bronstein, L. (2011). Strengthening interprofessional team collaboration: Potential roles for school mental health professionals. Advances in School Mental Health Promotion, 4(2), 51-60. https://doi.org/10.1080/1754730X.2011. 9715629

Mellin, E. A., Taylor, L., Weist, M. D., \& Lockhart, N. C. (2016). The expanded school mental health collaboration instrument [community version]: Development and initial psychometrics. School Mental Health, 8(2), 305-318. https://doi.org/10.1007/s12310-015-9164-x

Mellin, E. A., \& Weist, M. D. (2011). Exploring school mental health collaboration in an urban community: A social capital perspective. School Mental Health, 3(2), 81-92. https://doi.org/10.1007/ s12310-011-9049-6

Mickelson, R. A. (2003). When are racial disparities in education the result of racial discrimination? A social science perspective. Teachers College Record, 105(6), 1052-1086.
Nastasi, B. K. (2004). Meeting the challenges of the future: Integrating public health and public education for mental health promotion. Journal of Educational and Psychological Consultation, 15(3-4), 295-312. https://doi.org/10.1080/10474412.2004.9669519

National Academies of Sciences, Engineering, and Medicine. (2015). Mental disorders and disabilities among low-income children. Washington: National Academies Press. https://doi.org/10.17226/ 21780

National Center for Education Statistics. (2019). Common core of data (CCD)_Public elementary/secondary school universe survey data (ed.gov). Retrieved 2020, from https://nces.ed.gov/ccd/pubschuniv. asp.

National Center for School Mental Health. (2020a). School mental health quality guide: Teaming. University of Maryland School of Medicine.

National Center for School Mental Health. (2020b). School mental health quality guide: Early intervention and treatment services and supports. University of Maryland School of Medicine.

O'Mara, L., \& Lind, C. (2013). What do we know about school mental health promotion programmes for children and youth? Advances in School Mental Health Promotion, 6(3), 203-224. https://doi.org/10. 1080/1754730X.2013.811952

OSEP Technical Assistance Center on Positive Behavioral Interventions and Supports. (2015). Positive Behavioral Interventions and Supports (PBIS) implementation blueprint: Part 1-Foundations and supporting information. Eugene, OR: University of Oregon. Retrieved from www.pbis.org.

Phillippo, K., \& Stone, S. (2006). School-based collaborative teams: An exploratory study of tasks and activities. Children and Schools, 28(4), 229-235. https://doi.org/10.1093/cs/28.4.229

Rosenfield, S., Newell, M., Zwolski, S., Jr., \& Benishek, L. E. (2018). Evaluating problem-solving teams in $\mathrm{K}-12$ schools: Do they work? American Psychologist, 73(4), 407. https://doi.org/10.1037/amp00 00254

Stephan, S. H., \& Mayworm, A. M. (2017). The benefits of school mental health. In K. Michael \& J. Jameson (Eds.), Handbook of rural school mental health (pp. 3-16). Berlin: Springer. https://doi.org/10.1007/ 978-3-319-64735-7

Stratford, B., Cook, E., Hanneke, R., Katz, E., Seok, D., Steed, H., Fulks, E., Lessans, A., \& Temkin, D. (2020). A scoping review of school-based efforts to support students who have experienced trauma. School Mental Health, 12, 442-477. https://doi.org/10.1007/ s12310-020-09368-9

Sugai, G., Simonsen, B., Bradshaw, C., Horner, R., \& Lewis, T. (2014). Delivering high quality school-wide positive behavior support in inclusive schools. In J. McLeskey, N. L. Waldron, F. Spooner, \& B. Algozzine (Eds.), Handbook of effective inclusive schools: Research and practice (pp. 306-321). Routledge.

Vestal, C. (2018). States begin requiring mental health education in schools. Retrieved January 1, 2020, from National Alliance on Mental Illness. https://namivirginia.org/states-begin-requiring-mentalhealth-education-schools/

Villarreal, V., \& Castro-Villarreal, F. (2016). Collaboration with community mental health service providers: A necessity in contemporary schools. Intervention in Schools and Clinic, 52(2), 108-114. https:// doi.org/10.1177/1053451216636047

Walker, T. (2018). Are schools ready to tackle the mental health crisis? NEA News. Retrieved January 1, 2020, from https:// www.nea.org/advocating-for-change/new-from-nea/are-schoo ls-ready-tackle-mental-health-crisis

Weist, M. D. (1997). Expanded school mental health services: A national movement in progress. In T. H. Ollendick \& R. J. Prinz (Eds.), Advances in clinical child psychology (Vol. 19, pp. 319-352). Plenum. 
Weist, M. D., Lowie, J. A., Flaherty, L. T., \& Pruitt, D. (2001). Collaboration among the education, mental health, and public health systems to promote youth mental health. Psychiatric Services, 52(10), 1348-1351. https://doi.org/10.1176/appi.ps.52.10.1348

Whitney, D. G., \& Peterson, M. D. (2019). US national and state-level prevalence of mental health disorders and disparities of mental health care use in children. JAMA Pediatrics, 173(4), 389-391. https://doi.org/10.1001/jamapediatrics.2018.5399
Publisher's Note Springer Nature remains neutral with regard to jurisdictional claims in published maps and institutional affiliations. 